\title{
BLOG INTENTION BASED ON FASHION INVOLVEMENT AND TRUST
}

\author{
Ru-Jen Cheng \\ Vanung University/National Taipei University \\ No.1 Van-Nung Rd., Chung-Li, Tao-Yuan 32061, Taiwan \\ jenny@vnu.edu.tw \\ Wencheng Fang \\ National Taipei University \\ 151, University Rd., San Shia District, New Taipei City 23741, Taiwan \\ fang@mail.ntpu.edu.tw
}

\begin{abstract}
The perception of the value of a blog positively influences the intention to revisit a blog and adopt its ideas. Few studies have attempted to elucidate readers' behavior by examining the effect of trust and the involvement of fashion on the revisiting and adoption of fashion blogs. Trust and fashion involvement are new factors that influence the decision of young readers to revisit fashion blogs and adopt the recommendations of bloggers. Data were collected using an online survey distributed through the Tpaobj blog. In this study, 363 questionnaires were conducted and completed. The results partially support the model and hypotheses proposed in this study, and indicate that fashion involvement affects only the intention of a reader to revisit the blog, but not the intention to adopt its viewpoint. Furthermore, the results reveal that trust in a blog is positively related to the likelihood of readers revisiting a blog and adopting its viewpoint. In this paper, the implications of the findings and suggestions for future research are discussed.
\end{abstract}

Keywords: Fashion Involvement, Trust, Blog Intention

\section{INTRODUCTION}

Marketing messages are less effective since the Internet has changed many of the sources delivering information ${ }^{1}$. Consumers are exhausted by having too many options while using the Internet for information searches. Presently, blogs have become an essential tool for communication in contemporary society, from seeking advice to conveying personal views on a topic. According to a recent investigation from the Social Media Blog${ }^{2}$, 
$77 \%$ of Internet users read blogs and $74 \%$ search online for consumer electronic reviews before buying. Nearly 150 million blogs have been posted on the Internet, with over 27,000 new blogs created every 24 hours $^{3}$. What are the key factors influencing users' purchase decision-making while consulting a blog?

With the growing levels of ambition among the young to look better, their desires are often fueled by trends in other countries and a desire to keep up with the latest fashions. Since the late 1990s, fashion has changed rapidly. It is estimate that $\$ 250$ billion is spent on fashion (including accessories) in the U.S. each year ${ }^{4}$. The young are no longer satisfied by the basic functions of clothing, but now also seek out fashion knowledge. Fashion blogs are increasingly influential, primarily because they are updated frequently, and provide bloggers with a powerful platform for expressing their fashion-related opinions ${ }^{5}$. As fashion leaders, bloggers have come to recognize the importance of trend watching and keeping up with current fashion trends ${ }^{6}$. Additionally, blog readers can access a variety of opinions from bloggers to acquire inspiration, fashion, and beauty tips, and even suggestions for purchase decisions ${ }^{7}$.

Much of existing research into commercial uses of blogs has focused on understanding the impact of a blog on online shopping intentions in general $^{8}$. Unlike the general commercial industry, the unique characteristics of the fashion industry is 'fast fashion'. With fashion trends changing seasonally, consumers' demands for updated fashion information is high. Consumers no longer rely on their past knowledge and instead want to catch new fashion information. Fashion conscious consumers search for fashion news on the Internet, especially thru blogs specializing in fashions. Thus, it is necessary to investigate influential factors: advice-adoption and revisit intention in fashion blogs. The varying degrees of fashion involvement and trust exhibited by readers affect the frequency of visitation and the acceptance of the bloggers' recommendations. So far, there have only been a few studies on the influence of fashion involvement and trust in a specific blog on blog reader behavior and intrinsic motivation.

This study conducted an investigation of a particular fashion blogger (i.e., Tpaobj blog) and proposed a theoretical framework to investigate the influence of a specified fashion blog on readers in terms of revisiting and adoption of recommendations from a blog. The Tpaobj blog was established in May 2005 as an exchange for information on fashion trends in Japan. Since then, more than 10 million people had visited the blog, especially young girls in Taiwan. The blogger on this website did not accept any payment from vendors; consequently, her independent comments attracted blog readers who trusted her advice. Retaining readers and ensuring that 
they accept the product recommendations of the blogger have become one of the most vital objectives of many fashion blogs.

After a literature review of blog research, this study focused on applying the technology acceptance model (TAM) framework that included the influences of a specific blog on readers' behavior. Davis, Bagozzi, and Warshaw ${ }^{9}$ suggested that the intention to use technology can be predicted by perceived usefulness (PU) and perceived ease of use (PE). In addition, blogging is a voluntary behavior, varying from use of an IT system. When browsing fashion blogs, readers are concerned with product function as well as the fashionable atmosphere. Therefore, two new constructs, fashion involvement and trust, were introduced into the model. In general, fashion blog readers are determined to be fashion conscious, and therefore, seek

opinions from fashion blogs that they trust ${ }^{10,11}$. Overall, the findings indicated that there were statistically significant results for trust in blog readers' behavior, as well as fashion involvement on re-visitation of a blog in the extended TAM.

This paper recognized fashion blog readers as being a particular group and explained trust and fashion involvement by integrating previous studies in the literature. Following the conceptual framework, this paper proposes some hypotheses in order to demonstrate the relationship between fashion blog readers and bloggers. It also includes a research methodology that presents findings, culminating in conclusions and practical implications, limitations of the study, and finally suggestions for future studies.

\section{LITERATURE REVIEW, HYPOTHESES, AND RESEARCH MODEL}

\subsection{Theory Background}

TAM has been applied in various organizational information technology (IT) studies; however, few studies have been conducted to explain behavior toward fashion blogs. First, apart from fashion involvement and trust, researchers can focus on measuring perceived ease of use (PE) and perceived usefulness (PU), which are direct predictors of intentions $^{12}$. In this study, a simplified version of the TAM, which does not consider attitude, was created to explain blog reader behavior associated with fashion blogs.

Blogs have gained popularity among Internet users as an easy and useful communication tool. Poor user interfaces have caused some resistance to the technology. Blogs with easy access and user-friendly interfaces are conducive to usage. Most of blog readers habitually visit blogs for information or inspiration ${ }^{13}$. PU is based on the belief of blog 
readers that the information obtained from the blog can facilitate purchase decisions. Furthermore, the function of a blog to assist readers in accessing information enhances the PU of the blog. Finally, blog readers perceived the fashion information as a necessity that will eventually enhance re-visit to the blog. Similarly, if the blog can provide new fashion information, it will also increase the adoption of the recommendation from readers. Therefore, the following hypotheses were developed:

Hypothesis 1: PE is positively related to the PU of reading a blog.

Hypothesis 2a: PE is positively related to the intention to revisit a blog.

Hypothesis 2b: PE is positively related to the intention of blog adoption.

Hypothesis 3a: PU is positively related to the intention to revisit a blog.

Hypothesis 3b: PU is positively related to the intention of blog adoption.

In the TAM, the influence of PU and PE is insufficient to predict users' intention. Trust is also a vital factor in attracting returning customers, especially for online businesses ${ }^{14}$. In the online community, trust is considered a positive influential factor in a user's decision to share information ${ }^{15}$. Trust plays a vital role in maintaining a successful interpersonal relationship between bloggers and readers. Lee and Koo ${ }^{16}$ showed that consumers trust peer consumers and are likely to use information provided by other consumers to assess products before they make a purchase decision. Building trust and commitment in blog readers may lead them to revisit the blog, recommend it, or prefer it over other blogs ${ }^{17}$. Trust reduces uncertainty and provides expectations for a satisfactory blog experience, and thus, positively influences the behavioral intentions of blog readers to revisit the blog and adopt its ideas. In comparison with advertisements, bloggers' recommendations constitute an information channel. Consumers usually trust the recommendation from bloggers positively just because their opinions are non-commercial ${ }^{18}$. If blog readers trust a fashion blog, the effect of persuasion and frequency of revisit are increased. This evidence demonstrates that developing trust is critical for a blog. In this study, a positive relationship between trust and the intention of readers to revisit or adopt the ideas of a blog was assumed. Therefore, the following hypotheses were developed:

Hypothesis 4a: Trust is positively related to the intention of blog adoption.

Hypothesis 4b: Trust is positively related to the intention of revisiting a blog.

In addition, Agarwal and $\operatorname{Prasad}^{19}$ proposed that individual characteristics had not been included in the original TAM as they had significant impacts on technology acceptance and usage. Several studies 
have focused on ease of use, usefulness, trust, and other beliefs that affect the intention to use an IT system ${ }^{20}$. In addition to trust, readers might have different experiences with a blog based on individual interests with products and service. The present study integrates several individual level factors, trust and fashion involvement, as construct of the TAM.

The readers of a fashion blog are interested in the most recent fashion information, and mostly likely interact with bloggers to keep up with trends. Zaichknowsky ${ }^{21}$ defined involvement as a person's perception of the objective based on his or her inherent needs, values, and interests. Highly involved consumers assign more time, attention, and effort to seeking product-related information ${ }^{22,23}$. Fashion has been classified as high involvement with a strong association with personal identity ${ }^{24}$. Fashion involvement could significantly affect the information-seeking behavior of fashion blog readers. Thus, blog readers fulfill their need for information and search for confirmation from bloggers ${ }^{25}$. The adoption of ideas presented on a blog is influenced by the degree of involvement in fashion, which is defined by the desire of users to align their behavior with fashion trends. Numerous blog readers are influenced by bloggers and their recommendations of fashion trends. Others do not follow trends or adopt fashion tips from bloggers, but may seek advice on certain products and accept tips and recommendations that they believe are suited to them ${ }^{7}$. Therefore, in this study, readers who exhibited a high degree of fashion involvement were assumed to be more likely to visit fashion blogs and share fashion ideas than those with a low degree of fashion involvement. Fashion leadership is a crucial consumer characteristic because of the interpersonal influence of this factor in the consumption of apparel ${ }^{26}$.

The Tpaobj blog introduces Japanese fashion as a fashion leader in dress design. Tpaobj is a fashion information provider and advisor for later fashion adopters. In addition, readers with a high degree of fashion involvement spend considerable time on Tpaobj ${ }^{27}$. Fashion bloggers are able to convince readers to purchase certain products by providing in-depth information and demonstrating their expertise, thereby further promoting the acceptance of their recommendations ${ }^{25}$. The more readers that visit the blog, the more likely they are to accept the recommendations of a blogger. On the other hand, Mack, Blose, and Pan ${ }^{28}$ demonstrate that the effect of the blog postings was one type of awareness rather than persuasion. Some of the blog readers are only interested in fashion information and make decisions by themselves, especially prevalent among the young group. To elucidate the finding on readers' behavior from the previous literature, the study examined the involvement of young female blog readers in fashion products, and how this involvement may influence their re-visitation and adoption of the blog's recommendations. Therefore, the following 
hypotheses were formed:

Hypothesis 5a: Fashion involvement is positively related to the intention of revisiting a blog.

Hypothesis 5b: Fashion involvement is positively related to the intention of blog adoption.

Hypothesis 6: The intention to revisit a blog affects the intention of blog adoption.

\subsection{Research Model}

Figure 1 illustrates our research model, which hypothesizes that a blog reader's re-visitation and adoption are determined by belief in the ease to use, usefulness and fashion involvement of the blog and trust in the blogger. Usefulness of a blog is influenced by ease of use of the blog. Additionally, trustworthiness of the blogger and fashion involvement of blog readers on blog intention is encompassed in our research model.

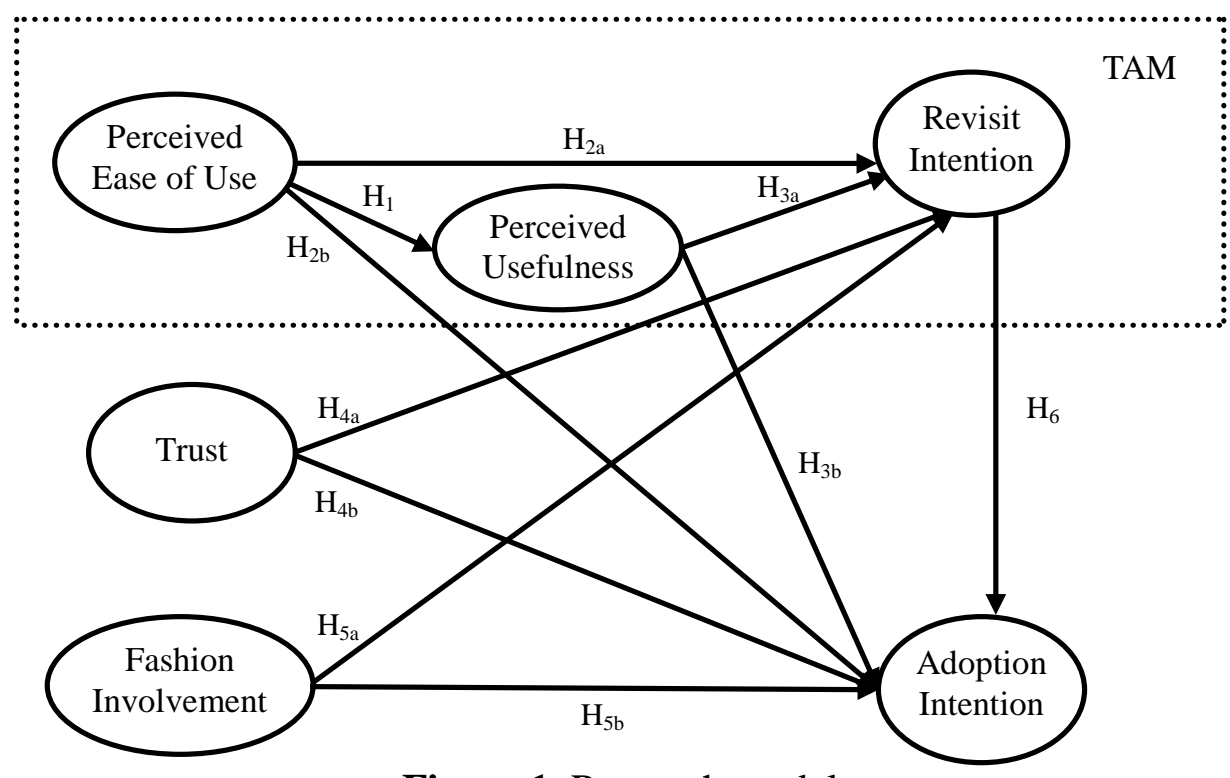

Figure 1. Research model

\section{METHODOLOGY}

\subsection{Samples}

This study utilized a survey research design, and the readers of Tpaobj's blog comprised the main participant samples for this study. Three hundred sixty-three completed questionnaires were collected on the Tpaobj's blog that is a popular fashion dressing blog in Taiwan. 
Questionnaires were analyzed using structural equation modeling. Male and female made up $20.11 \%$ and $79.89 \%$, respectively. The data showed that more females than males visited the fashion blog. In consideration of the visitation rate, the percentage of frequent browsing of the blog per week was 42.98\%. Most of the respondents visited the blog 6 to 10 times per week, and they used blogs to obtain the information they needed.

\subsection{Questionnaire Design}

The questionnaire used for data collection contained scales to measure the various constructs of this research model. It included respondents' demographic characteristics and blog readers' willingness to revisit or adopt the blog. The questionnaire was divided into two sections. In the first section of the questionnaire, Davis' study was used, of which has been validated in numerous studies. The scales were slightly modified to fulfill the context of a blog. The questionnaire revised PE (3 items), PU (3 items), and intention for adoption (3 items), intention to revisit (3 items) from Bhattacherjee $^{29}$, trust ( 3 items) from Garbarino and Johnson ${ }^{30}$, and fashion involvement ( 3 items) from McIntyre and Miller ${ }^{31}$. Respondents indicated their agreement or disagreement with the survey instruments using a seven-point Likert-type scale, ranging from "strongly disagree" (1) to "strongly agree" (7). The second section of the questionnaire was demographic information from the respondents, such as gender, and the time spent on blog browsing on a weekly basis.

Before conducting the main survey, the wording of the scales and the format of the questionnaires were revised. Next, to reduce possible ambiguity in the items, a pilot test involving 50 respondents selected from college students was administered. The results of the pilot tests showed acceptable reliability and validity of the measurements.

\subsection{Measurement Development}

The measurement model was assessed by using confirmatory factor analysis, which demonstrated excellent overall model fit indices. Confirmatory factor analysis on all items showed a satisfactory fit with chi square $\left(\chi^{2}\right)$ of $402.94(d f=121 ; p<0.001)$ and other fit indices: $\mathrm{CFI}=0.96$, $\mathrm{IFI}=0.96, \mathrm{NNFI}=0.95, \mathrm{RMR}=0.044, \mathrm{RMSEA}=0.08$.

Item reliability was assessed by examining the loading of the measures with their respective constructs. Items with loading higher than 0.7 are desirable. As shown in Table 1 listed below, Cronbach's alpha values for all constructs ranged from 0.874 (for fashion involvement) to 0.976 (for intention to adopt), indicating the existence of reliability. Convergent validity was assessed by the closeness of the two measures within the same construct $^{32}$. Composite reliability (CR) and average variance extracted 
(AVE) for each construct exceeded 0.5, indicating that items captured more variance in the underlying construct than measurement error doses ${ }^{33}$. In this study, all factor loadings for items were statistically significant with t-value ranging from 14.86 to 25.91 . Besides CR (ranging from 0.83 to 0.97 ) and AVE (ranging from 0.63 to 0.92 ), all exceeded the acceptable value of 0.50 . This showed that the internal consistency of our model was sufficient.

Table 1. Standardized loadings and reliability

\begin{tabular}{ccccc}
\hline Indicators & $\begin{array}{c}\text { Standardized } \\
\text { Loading }\end{array}$ & AVE & CR & Cronbach's $\alpha$ \\
\hline PE1 & $0.89(t=21.26)$ & 0.75 & 0.90 & 0.895 \\
PE2 & $0.88(t=20.62)$ & & & \\
PE3 & $0.83(t=19.00)$ & & & \\
PU1 & $0.92(t=22.61)$ & 0.80 & 0.92 & 0.929 \\
PU2 & $0.90(t=21.90)$ & & & \\
PU4 & $0.86(t=20.19)$ & & & \\
TR1 & $0.93(t=23.20)$ & 0.63 & 0.83 & 0.938 \\
TR2 & $0.94(t=23.45)$ & & & \\
TR4 & $0.87(t=20.58)$ & & & \\
FI1 & $0.91(t=21.58)$ & 0.68 & 0.86 & 0.874 \\
FI2 & $0.84(t=18.91)$ & & & \\
FI3 & $0.71(t=14.86)$ & & & \\
RI1 & $1.00(t=25.91)$ & 0.63 & 0.84 & 0.953 \\
RI2 & $0.83(t=19.42)$ & & & \\
RI3 & $0.92(t=22.89)$ & & & 0.976 \\
AI1 & $0.95(t=24.36)$ & 0.92 & 0.97 & \\
AI2 & $0.97(t=25.43)$ & & & \\
AI3 & $0.96(t=25.00)$ & & & \\
\hline Not PE & &
\end{tabular}

Note: $\mathrm{PE}=$ perceived ease of use on blog; $\mathrm{PU}=$ perceived usefulness on blog; $\mathrm{TR}=$ trust in blogger; $\mathrm{FI}$ = fashion involvement on blog; $\mathrm{RI}=$ revisit intention on blog; $\mathrm{AI}=$ intention to adopt blog.

As shown in Table 2 listed below, the mean value of the PE had the highest value followed by re-visitation or adoption. PE and trust constructs had very similar mean values. This can be interpreted as trust having a greater influence on a reader's re-visitation or adoption. In order to examine the relationships between independent variables and dependent variables, further research and hypothesis testing is needed. 
Table 2. Means, standard deviations, and correlations

\begin{tabular}{lllllllll}
\hline & Means & SD & PE & PU & TR & FI & RI & AI \\
\hline PE & 5.70 & 1.02 & 1 & - & - & - & - & - \\
PU & 5.38 & 1.17 & 0.694 & 1 & - & - & - & - \\
TR & 5.67 & 1.16 & 0.716 & 0.708 & 1 & - & - & - \\
FI & 5.27 & 1.15 & 0.604 & 0.623 & 0.565 & 1 & - & - \\
RI & 5.69 & 1.34 & 0.708 & 0.785 & 0.800 & 0.613 & 1 & - \\
AI & 5.62 & 1.19 & 0.694 & 0.729 & 0.765 & 0.580 & 0.770 & 1 \\
\hline
\end{tabular}

Note: $* p<.01 ; \mathrm{PE}=$ perceived ease of use on blog; $\mathrm{PU}=$ perceived usefulness on blog; TR = trust in blogger; FI = fashion involvement on blog;

$\mathrm{RI}=$ revisit intention on blog; $\mathrm{AI}=$ intention to adopt blog.

Discriminant validity is obtained if the measure of a construct is not correlated with measures of other different constructs ${ }^{32}$. It is attained by conducting a series of chi-square difference tests using measures of each pair of constructs ${ }^{34,35}$. The important and critical advantage of the chi-square difference test is that it allows for simultaneous pair-wise comparisons for the constructs. If the chi-square difference test (with $1 \mathrm{df}$ ) between the constrained model and the unconstrained model is significant, which means that two constructs are viewed as different, then discriminant validity is manifested. The constrained model is obtained by setting the correlation between two constructs to 1 , but allowing other constructs to co-vary. By calculating the Bonferroni method under overall 0.01 levels, the critical values of the chi-square test were $\chi 2(1,0.01 / 15)=11.58^{36,37}$. Since all the chi-square differences for every two constructs exceeded 40.24, as shown in Table 3, discriminant validity was successfully achieved.

\section{RESULTS}

\subsection{Assessment of the Effects of Common Method Variance}

Because all the measures were self-reported by the same respondents, there is a potential problem for the occurrence of common method variance (CMV). Thus, we used Harmon's one-factor test to assess the possibility of common method variance. All items were analyzed in principal component factor analysis with varimax rotation. If common method variance exists, then all items will be found in a single general factor, which accounted for over $50 \%$ of the variance. In this study, the first emerging factor accounted for $16.685 \%$ of the variance, and all six factors together accounted for $85.774 \%$ of the variance. As a result, there is no single factor emerging from the factor analysis, suggesting that there is little chance of the possibility of common method bias. 
Table 3. Chi-square difference tests

\begin{tabular}{ccc}
\hline $\begin{array}{c}\text { Construct } \\
\text { Pair }\end{array}$ & Unconstrained & $\chi^{2}(121)=402.94$ \\
Constrained $\chi^{2}(122)$ & $\chi^{2}(1)$ & difference \\
\hline (PE, PU) & 764.94 & 362 \\
(PE, TR) & 713.22 & 310.28 \\
(PE, FI) & 714.52 & 311.58 \\
(PE, RI) & 802.05 & 399.11 \\
(PE, AI) & 760.22 & 357.28 \\
(PU, TR) & 918.48 & 515.54 \\
(PU, FI) & 732.40 & 329.46 \\
(PU, RI) & 966.51 & 563.57 \\
(PU, AI) & 886.86 & 483.92 \\
(TR, FI) & 725.43 & 322.49 \\
(TR, RI) & 807.85 & 404.91 \\
(TR, AI) & 884.56 & 481.62 \\
(FI, RI) & 740.96 & 338.02 \\
(FI, AI) & 727.99 & 325.05 \\
(RI, AI) & 1275.81 & 872.87 \\
\hline
\end{tabular}

Note: *Significant at the .05 overall significance level; $* *$ Significant at the .01 overall significance; $\mathrm{PE}=$ perceived ease of use on blog; $\mathrm{PU}=$ perceived usefulness on blog; TR = trust in blogger; $\mathrm{FI}=$ fashion involvement on blog; $\mathrm{RI}=$ revisit intention on blog; $\mathrm{AI}=$ intention to adopt blog.

\subsection{Hypothesis Testing}

LISREL 8.54 software was used to assess the measurements and structural models. The proposed model demonstrated acceptable goodness of fit $\left(\chi^{2} / d f=442.95 / 123=3.60\right.$; confidence interval $=0.96$, IFI $=0.96$, $\mathrm{NNFI}=0.95, \mathrm{GFI}=0.88, \mathrm{RMR}=0.09$, root mean square error of approximation $=0.08$ ). Table 4 and Figure 2 present the results of the structural model with the standardized path coefficients between the constructs. The hypothesized paths derived from PE, PU, fashion involvement, and trust were considered significant in the structural equation model used for predicting the intention to revisit or adopt the blog's recommendations. PU (path coefficients of $0.8, t=16.31, p<.001$ ) was significantly influenced by $\mathrm{PE}$, and the re-visitation of the blog was significantly affected by trust (path coefficients of $0.45, t=5.51, p<.001$ ), fashion involvement (path coefficients of $0.20, t=4.03, p<.001$ ), and PU (path coefficients of $0.32, t=5.29, p<.001$ ). Adoption of the blog was significantly influenced by trust (path coefficients of $0.43, t=5.17, p$ $<.001$ ) and PU (path coefficients of $0.27, t=4.08, p<.001$ ). The analysis results supported $\mathrm{H}_{1}$ : the PE positively affects PU. However, $\mathrm{H}_{2}(\mathrm{PE})$ that affects the re-visitation or adoption of the fashion blog was not supported by 
the data. $\mathrm{H}_{5 \mathrm{~b}}$ and $\mathrm{H}_{6}$ after a t test was conducted for the path coefficients were not supported. Nevertheless, $\mathrm{H}_{3}, \mathrm{H}_{4}$, and $\mathrm{H}_{5 \mathrm{a}}$ were supported. $\mathrm{PE}$ had an indirect effect through the mediation of PU. These results indicated that PU and trust affected re-visitation and blog adoption directly. Fashion involvement affected only the re-visitation of the blog.

Table 4. Path coefficients and $\mathrm{t}$-values

\begin{tabular}{lcc}
\hline Hypothesis & $\begin{array}{c}\text { Standardized } \\
\text { Coefficient }\end{array}$ & t Value \\
\hline $\mathrm{H}_{1}(\mathrm{PE} \rightarrow \mathrm{PU})$ & 0.80 & $16.31 * * *$ \\
$\mathrm{H}_{2 \mathrm{a}}(\mathrm{PE} \rightarrow \mathrm{RI})$ & 0.05 & 0.5 \\
$\mathrm{H}_{2 \mathrm{~b}}(\mathrm{PE} \rightarrow \mathrm{AI})$ & 0.11 & 1.13 \\
$\mathrm{H}_{3 \mathrm{a}}(\mathrm{PU} \rightarrow \mathrm{RI})$ & 0.32 & $5.29 * * *$ \\
$\mathrm{H}_{3 \mathrm{~b}}(\mathrm{PU} \rightarrow \mathrm{AI})$ & 0.27 & $4.08 * * *$ \\
$\mathrm{H}_{4 \mathrm{a}}(\mathrm{TR} \rightarrow \mathrm{RI})$ & 0.40 & $5.51 * * *$ \\
$\mathrm{H}_{4 \mathrm{~b}}(\mathrm{TR} \rightarrow \mathrm{AI})$ & 0.43 & $5.17 * * *$ \\
$\mathrm{H}_{5 \mathrm{a}}(\mathrm{FI} \rightarrow \mathrm{RI})$ & 0.20 & $4.03 * * *$ \\
$\mathrm{H}_{5 \mathrm{~b}}(\mathrm{FI} \rightarrow \mathrm{AI})$ & 0.04 & 0.85 \\
$\mathrm{H}_{6}(\mathrm{RI} \rightarrow \mathrm{AI})$ & 0.09 & 1.46 \\
\hline Notes: $* p<.05 ; * *<<.01 ; * * p<.001$.
\end{tabular}

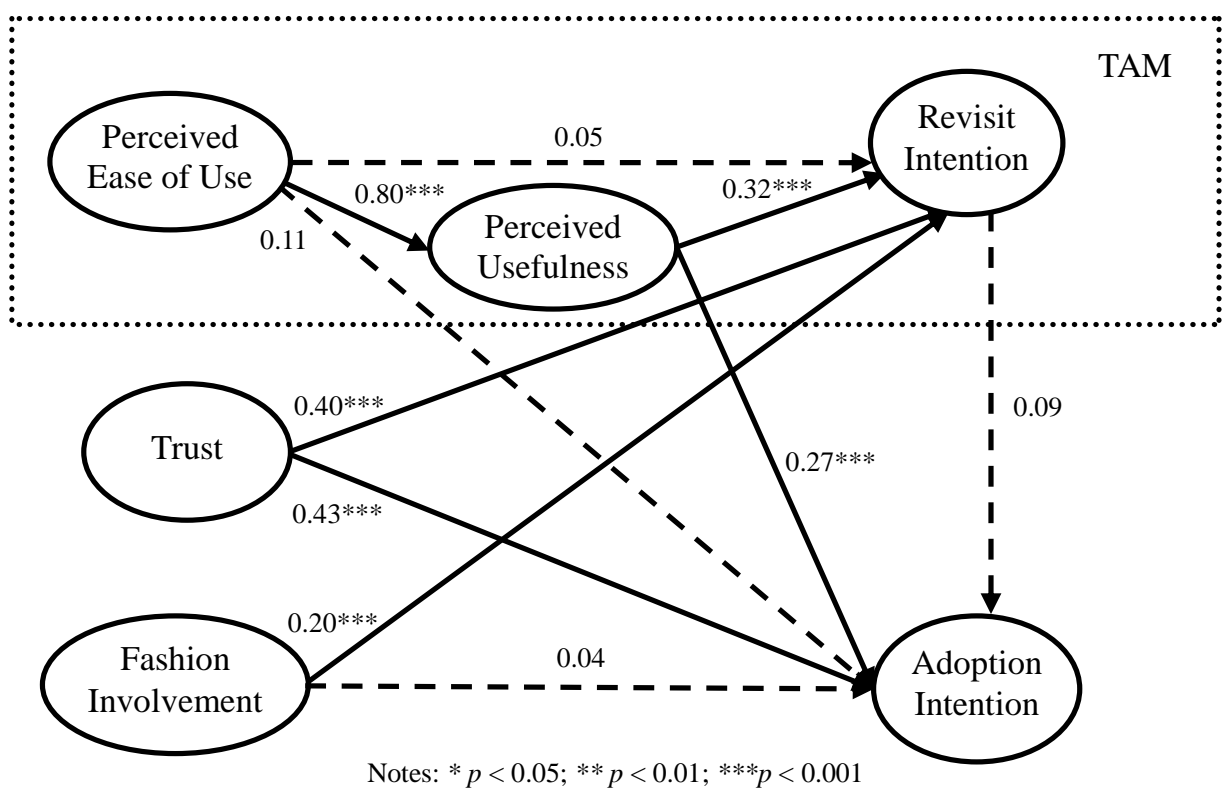

Figure 2. Results of the proposed model 


\section{DISCUSSION}

In this paper, we proposed an extended TAM integrated with two factors (i.e., trust and fashion involvement) to better investigate fashion blogs. The focal point was a consideration of the intention of fashion blog readers to revisit a blog and adopt blogger recommendations. The results demonstrated that most paths of the proposed model (six out of ten) were supported.

The empirical results indicate that PE increases the PU of a fashion blog. This substantiates the claim that the majority of blog readers in Taiwan are motivated to read a blog because exchanging and acquiring information is easy when using blogs 6 . However, PE does not directly affect blog re-visitation or the adoption of ideas within. The results of this study were in accordance with the David research on PE, and did not support the relationship between ease of use and usage ${ }^{38}$. This is because PE affects acceptance through $\mathrm{PU}^{39}$. This study demonstrated that providing useful information to readers is vital for bloggers because it attracts future visitors to the blog, and persuades the readers to accept blogger recommendations. Therefore, PU is proposed as the main determinant of acceptance for blog readers to revisit or adopt the blog's recommendations. In addition to PU, an additional two factors were included in the proposed model.

Trust was the most influential factor for both the intention to revisit a blog and to adopt product recommendations provided by bloggers. The result was consistent with those of previous studies, indicating that exhibiting trust positively affects the intention to use IT systems ${ }^{15,17}$. Therefore, to retain readers on the blog and to keep their influence with the adoption of recommendation, bloggers must endeavor to win their readers trust.

Fashion involvement also considerably affects the intention to use a fashion blog, but does not affect the adoption of product recommendations. The results indicate that the more readers are involved in fashion, the more likely they are to revisit fashion blogs. The fashion blog provides sufficient fashion information, such as beauty product reviews, fashion tips, and exclusive inside information. In other words, blog reading often becomes habitual $^{13,40}$, despite the readers' lack of interest in the content of certain posts they read. Readers with high fashion involvement are not affected by blogger recommendations regarding beauty products and clothes. One possible reason is that those who are highly involved in fashion have distinct preferences regarding personal style. Moreover, various blogs may offer conflicting opinions. It is not easy for them to follow any "specific" person's advices. The information they obtain from a blog is most likely only one of numerous sources that they have consulted. Sherif, Sherif, and 
Nebergall ${ }^{41}$ assumed that people who are highly involved in a topic are likely to evaluate all possible situations. High involvement also means that people have a restricted range of acceptance ${ }^{42}$. In summary, a blog reader who is involved in fashion is difficult to persuade. In short, the findings indicated that fashion involvement and trust had significant effects on blog readers' behaviors. Furthermore, bloggers' recommendation may be a promising marketing strategy for increasing sales.

\section{IMPLICATIONS, LIMITATIONS AND FUTURE RESEARCH}

\subsection{Implications}

This study provided a theoretical basis for the factors that promote the personal use of fashion blogs. Models with good fit explain blog reader behavior more effectively than the TAM. The two factors added in this study, trust and fashion involvement, increased the explanatory power of the proposed model for fashion blog reader behavior. Examining the effectiveness of other blog types, such as travel blogs, is necessary for researchers because trust and fashion involvement are likely to affect the revisit and adoption of a variety of blogs.

This study has several practical implications. First, the enrichment of professional knowledge and the honest reporting of product trials could enhance user trust in a blog. Feature reviews, latest fashion information, and personal product experience can all increase user trust in a blog. Second, blogs should provide useful new information, including information on product effectiveness or fashion information, suited to user needs. For example, the blog must provide readers with a source of inspiration. Moreover, readers are more easily attracted by pictures or images presented by the blog, further enhancing trust. Constantly updating postings of the blog with new information, such as daily outfits, DIY tips, and photos, is required. Thirdly, information presentation in the blog has a strong impact on readers' perception. Designing the blog to raise readers' awareness and responsiveness could be valuable in transforming routine blog reading into engaging experience. If the blogger consistently posts useful contents, it will eventually contribute to solidifying the values of his or her blog. When readers perceived the value of blog, they will adopt the blogger's recommendation. Fourth, bloggers must consider methods for retaining their readers. For example, bloggers can excite their readers by creating demands for exclusivity, secrecy. Finally, providing holistic information can enhance reader knowledge and fulfill their desire for fashionable apparel and cosmetics, which subsequently increases the level of involvement and loyalty to the blog. The findings were expected to clarify and facilitate the 
development of marketing strategies to promote products and services.

\subsection{Limitations and Future Research}

Although this study yielded findings that have both theoretical and practical implications, the study design has several limitations. First, the majority of the participants were female, meaning that the analytical results are limited in generalization. Enlarging the survey samples, such as including users of sports blogs, might facilitate the identification of potential problems and provide comparative results. Second, fashion involvement affects only the revisit of the blog, but not the adoption of blogger recommendations. Other determinants, such as reader habits and subjective norms, are suggested for future research. Moreover, high involvement means that people have a restricted range of acceptance ${ }^{42}$. It is necessary to distinguish readers with different level of involvements for a further investigation. Third, this study demonstrated that trust is a vital factor in blog adoption. As argued in this paper, numerous types of trust are involved. A close examination of the detailed facets of trust should be conducted to yield an unbiased result, which could serve as a promising basis for future research. Fourth, the usefulness of blogs needs to be emphasized in clear design and as an easily used tool to attract more readers, and this may serve as a mediator between fashion involvement and adoption.

\section{CONCLUSIONS}

In this study, the original TAM was adjusted, and the factors of trust and fashion involvement were included for analysis of a fashion blog. A major finding was that the effect of revisiting and adopting a fashion blog on reader behavior can be observed through the PU, trust, and fashion involvement of the reader. By identifying the factors influencing the intention to use fashion blogs and their implications, the results of this study can be used to increase the frequency that readers visit the fashion blog and accept blogger recommendations. Among various marketing methods used to appeal to younger generations, blogs are an extremely effective tool.

\section{REFERENCES}

[1] L.-C. Lu, W.-P. Chang, and H.-H. Chang, Consumer attitude blogger's sponsored recommendations and purchase intention: The effect of sponsorship type, product type, and brand awareness, Computer in Human Behavior, 34, p258-266, 2014. http://dx.doi.org/10.1016/j.chb.2014.02.007.

[2] Social Media Blog, 15 blogger stats 2013. Retrieved on May 26, 2014 from

http://www.magnetsocialmedia.com/blog/15-blogger-statistics-2013. 
[3] BlogPulse, Blogpulse stats. Retrieved on May 26, 2014 from http://www.kerrmunications.co.uk/2011/06/one-hundred-and-fifty-sixmillion-and-one/.

[4] Statistic Brain, Fashion industry statistics. Retrieved on May 26, 2014 from http://www.statisticbrain.com/fashion-industry-statistics/.

[5] G. Morandin, R.P. Bagozzi, and M. Bergami, Brand community membership and the construction of meaning, Scandinavian Journal of Management, 29(2), p173-183, 2013. http://dx.doi.org/10.1016/j.scaman.2013.03.003.

[6] H. Kim, and B. Jin, Exploratory study of virtual communities of apparel retailers, Journal of Fashion Marketing and Management, 10(1), p41-55, 2006. http://dx.doi.org/10.1108/13612020610651114.

[7] J. Matikainen, Advertising in fashion blogs. Retrieved on March 20, 2014 , from http://www.theseus.fi/bitstream/handle/10024/46923/Matikainen_Jaana .pdf? sequence $=1$.

[8] C.L. Hsu, J.C.C. Lin, and H.S. Chiang, The effects of blogger recommendations on customers' online shopping intentions. Internet Research, 23(1), p69-87, 2013.

[9] F.D. Davis, R.P. Bagozzi, and P.R. Warshaw, User acceptance of computer technology: A comparison of two theoretical models. Management Science, 35(8), p982-1003, 1989. http://dx.doi.org/10.1287/mnsc.35.8.982.

[10] R. Lohtia, N. Donthu, and M. Guillory, The impact of advertising, trustworthiness, and valence on the effectiveness of blogs. International Journal of Electronic Marketing and Retailing, 5(4), p317-339, 2013. http://dx.doi.org/10.1504/IJEMR.2013.060264.

[11] T.J. Johnson, and B.K .Kaye, Wag the blog: How reliance on traditional media and the internet influence credibility perceptions of weblogs among blog users. Journalism \& Mass Communication Quarterly, 81(3), p622-42, 2004. http://dx.doi.org/10.1177/107769900408100310.

[12] D.A. Adams, R.R. Nelson and P.A. Todd, Perceived usefulness, ease of use, and usage of information technology: A replication. MIS Quarterly, 16(2), p227-247, 1992. http://dx.doi.org/10.2307/249577.

[13] E. Bauer, M. Sueyoshi, and B. Tomlinson, Exploring the role of the reader in the activity of blogging. In M. Czerwinski and A. Lund (Eds.), Proceedings of the SIGCHI Conference on Human Factors in Computing Systems (p1111-1120). Florence, Italy: ACM Press, 2008. http://dx.doi.org/10.1145/1357054.1357228.

[14] S.W. Hung, M.J. Cheng, and P.C. Chen, Reexamining the factors for trust in cultivating online customer repurchase intentions: The moderating effect of perceived waiting. International Journal of Human-Computer Interaction, 28(10), p666-677, 2012. 
http://dx.doi.org/10.1080/10447318.2011.654201.

[15] W. Hong, J.Y.L. Thong, W.M. Mong, and K.Y. Tam, Determinants of user acceptance of digital libraries: An empirical examination of individual differences and system characteristics. Journal of Management Information Systems, 18(3), p97-124, 2001.

[16] K.T. Lee, and D.M. Koo, Effects of attribute and valence of e-WOM on message adoption: Moderating roles of subjective knowledge and regulatory focus. Computer in Human Behavior, 28(5), p1974-1984, 2012. http://dx.doi.org/10.1016/j.chb.2012.05.018.

[17] N.A.M. Noor, Trust and commitment: Do they influence e-customer relationship performance? International Journal of Electronic Commerce Studies, 3(2), p281-296, 2012. http://dx.doi.org/10.7903/ijecs.1096.

[18] N. Bhatnagar, L. Aksoy, and Selin A. Malkoc, Embedding brands within media content: The impact of message, media, and consumer characteristics on placement efficacy. In L.J. Shrum (Ed.), The psychology of entertainment media (p99-116). Mahwah, NJ: Lawrence Erlbaum.

[19] R. Agarwal, and J. Prasad, Are individual differences germane to the acceptance of new information technologies? Decision Sciences, 30(2), p361-391, 1999. http://dx.doi.org/10.1111/j.1540-5915.1999.tb01614.x.

[20] L.C. Har, and U.C. Eze, Factors influence consumers' intentions to repurchase online in Malaysia. International Journal of Electronic Commerce Studies, 2(2), p157-164, 2011.

[21] J. Zaichkowsky, Measuring the involvement constructs. Journal of Consumer Research, 12(3), p341-52, 1985. http://dx.doi.org/10.1086/208520.

[22] R.L. Celsi, and J.C. Olson, The role of involvement in attention and comprehension processes. The Journal of Consumer Research, 15(2), p210-224, 1988. http://dx.doi.org/10.1086/209158.

[23] A.E. Fairhurst, L.K. Good, and J.W. Gentry, Fashion involvement: An instrument validation procedure. Clothing and Textiles Research Journal, 7(3), p10-14, 1989. http://dx.doi.org/10.1177/0887302X8900700302.

[24] J. Wolny, and C. Mueller, Analysis of fashion consumers' motives to engage in electronic word-of-mouth communication through social media platforms. Journal of Marketing Management, 29(5-6), p562-583, 2013. http:/dx.doi.org/10.1080/0267257X.2013.778324.

[25] G. Khodadad, Fashionfever - A study on the fashion bloggers' influence on the MeWe-generation's fashion consumption. Retrieved May 26, 2014, from http://bada.hb.se/handle/2320/6769.

[26] H.S. Kim, H. Hong, Fashion leadership and hedonic shopping motivations of female consumers. Clothing \& Textiles Research 
Journal, 29(4), p314-330, 2011. http://dx.doi.org/10.1177/0887302X11422819.

[27] R.E. Goldsmit, and M.T. Stith, The social values of fashion innovators. Journal of Applied Business Research, 9(1), p10-16, 1992.

[28] R.W. Mack, J.E. Blose, and B. Pan, Believe it or not: Credibility of blogs in tourism. Journal of Vacation Marketing, 14(2), p133-144, 2008. http:/dx.doi.org/10.1177/1356766707087521.

[29] A. Bhattacherjee, An empirical analysis of the antecedents of electronic commerce service continuance. Decsion Support Systems, 32(2), p201-214, 2001. http://dx.doi.org/10.1016/S0167-9236(01)00111-7.

[30] E. Garbarino, and M.S. Johnson, The differential roles of satisfaction, trust, and commitment in customer relationships. Journal of Marketing, 63(2), p70-87,1999.

[31] S.H. McIntyre, and C.M. Miller, Social utilities and fashion theory. Marketing Letters, 1(3-4), p371-382, 1992.

[32] M. Viswanathan, Measurement error and research design. Thousand Oaks, CA: Sage Pubns, 2005.

[33] J.F. Hair, R.E. Anderson, R.L. Tatham, and W.C. Black, Multivariate data analysis (5th ed.). New Jersey: Prentice-Hall, 1998.

[34] J .Anderson, and D. Gerbing, Structural equation modeling in practice: A review and recommended two-step approach. Psychological Bulletin, 103(3), p411-423,

1988. http://dx.doi.org/10.1037/0033-2909.103.3.411.

[35] C. O'Reilly, and J. Chatman, Organizational commitment and psychological attachment: The effects of compliance, identification, and internalization on prosocial behavior. Journal of Applied Psychology, 71(3), p492-499, 1986. http://dx.doi.org/10.1037/0021-9010.71.3.492.

[36] R. Bagozzi, and Y. Yi, On the evaluation of structural equation models. Journal of the Academy of Marketing Science, 16(1), p74-94, 1988. http://dx.doi.org/10.1007/BF02723327.

[37] L. Hatcher, A step-by-step approach to using the SAS system for factor analysis and structural equation modeling. Cary, NC: SAS Publishing, 1994.

[38] D. Gefen, and M. Keil, The impact of developer responsiveness on perceptions of usefulness and ease of use: An extension of the technology acceptance model. ACM SIGMIS Database, 29(2), p35-49, 1998. http://dx.doi.org/10.1145/298752.298757.

[39] T. Pikkarainen, K. Pikkarainen, H. Karjaluoto and S. Pahnila, Consumer acceptance of online banking: an extension of technology acceptance. Internet Research, 14(3), p224-235, 2004. http://dx.doi.org/10.1108/10662240410542652.

[40] C. Liao, P.-L. To, and C.-C. Liu, A motivational model of blog usage. 
Online Information Review, 37(4), p620-637, 2013. http://dx.doi.org/10.1108/OIR-02-2012-0032.

[41] C.W. Sherif, M.S. Sherif, and R.E. Nebergall, Attitude and attitude change: The social judgment-involvement approach. Philadelphia: W.B. Saunders, 1965.

[42] judgment-involvement approach. Philadelphia: W.B. Saunders, 1965.C. I. Hovland, and M. Sherif, Social Judgment (Reprint from 1961 ed.). Westport: Greenwood Yale University Press, 1980. 